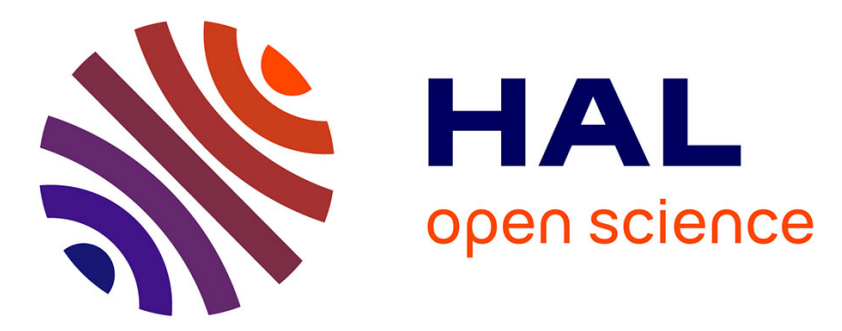

\title{
MGM deconvolution of complex mafic mineralogy rock slab spectra from visible-near infrared imaging spectroscopy: implications for the characterization of the terrestrial ocean crust and of the lunar crust
}

P.C. Pinet, D Glenadel-Justaut, Y Daydou, G Ceuleneer, S Gou, P Launeau, S D Chevrel, C Carli

\section{To cite this version:}

P.C. Pinet, D Glenadel-Justaut, Y Daydou, G Ceuleneer, S Gou, et al.. MGM deconvolution of complex mafic mineralogy rock slab spectra from visible-near infrared imaging spectroscopy : implications for the characterization of the terrestrial ocean crust and of the lunar crust. 8th Workshop on Hyperspectral Image and Signal Processing - Evolution in Remote Sensing (WHISPERS), Aug 2016, Los Angeles, United States. hal-03455649

\author{
HAL Id: hal-03455649 \\ https://hal.science/hal-03455649
}

Submitted on 29 Nov 2021

HAL is a multi-disciplinary open access archive for the deposit and dissemination of scientific research documents, whether they are published or not. The documents may come from teaching and research institutions in France or abroad, or from public or private research centers.
L'archive ouverte pluridisciplinaire HAL, est destinée au dépôt et à la diffusion de documents scientifiques de niveau recherche, publiés ou non, émanant des établissements d'enseignement et de recherche français ou étrangers, des laboratoires publics ou privés. 


\title{
MGM DECONVOLUTION OF COMPLEX MAFIC MINERALOGY ROCK SLAB SPECTRA FROM VISIBLE-NEAR INFRARED IMAGING SPECTROSCOPY : IMPLICATIONS FOR THE CHARACTERIZATION OF THE TERRESTRIAL OCEAN CRUST AND OF THE LUNAR CRUST
}

\author{
P. C. Pinet ${ }^{1,3}$, D. Glenadel-Justaut ${ }^{1,3}$, Y. Daydou ${ }^{1,3}$, G. Ceuleneer ${ }^{1,4}$, S. Gou ${ }^{1,2}$, P. Launeau ${ }^{5}$, \\ S. D. Chevrel ${ }^{1,3}$, C. Carli $^{6}$
}

${ }^{1}$ Université de Toulouse; UPS-OMP; IRAP; Toulouse, France, ${ }^{2}$ Institute of Remote Sensing and Digital Earth, Beijing, China; ${ }^{3}$ CNRS, IRAP, 14, avenue Edouard Belin, F-31400 Toulouse, France; ${ }^{4}$ CNRS, GET, 14, avenue Edouard Belin, F-31400 Toulouse, France ; ${ }^{5}$ LPGN, Nantes, France. ; ${ }^{6}$ IAPSINAF, Roma, Italy.

\begin{abstract}
Successive studies have shown the interest of the MGM approach for planetary surface characterization. However, these reference studies mainly deal with spectra acquired on controlled laboratory powder samples. Advanced imaging spectroscopic sensors with very high spatial resolution observations, either from orbit or in situ, give access to measurements at the scale of the outcrops down to the microscopic scale. At these scales, the coarse textures of the rock slabs may prevail over the granular nature of the surface. MGM deconvolution is tested here on Stillwater Complex and oceanic drill core slab samples with implications for the study of mafic assemblages in the presence of crystalline plagioclase such as in the lunar highlands crust.
\end{abstract}

Index Terms - imaging spectroscopy, crystalline plagioclase, mgm deconvolution, oceanic drilling, lunar crust

\section{INTRODUCTION}

Recent observations from the multiband imager and the spectral profiler onboard the Japanese SELENE spacecraft and from the Moon Mineralogy Mapper imaging spectrometer onboard the Chandrayaan mission identified in a number of lunar regions of the lunar crust (e.g., in crater central peaks) the unambiguous occurrence of a $1.2-1.25 \mu \mathrm{m}$ spectral feature, indicative of a crystal field absorption consistent with Fe-bearing plagioclase feldspar in anorthosite [1], also confirmed by the Diviner LR Experiment onboard the Lunar Reconnaissance Orbiter [2]. However, given the wealth of the M3 dataset, advanced hyperspectral processing appears needed to fully explore the existing variability involving plagioclase and mafic crystal field absorptions [3, 4], and to constrain the crustal lithology and stratigraphy of the lunar Highlands.

\section{BACKGROUND ON EARLIER MGM WORKS}

The principle of the Modified Gaussian Model is to deconvolve overlapping absorptions of mafic mineral spectra into their fundamental absorption components. The specific interest of this model is to directly account for electronic transition processes [e.g.,5]. Consequently, the MGM approach is in essence able to achieve a direct detection and quantification of minerals which make up the observed surface.

The work by [5] relied on the fact that spectrum variations in visible and near-infrared are caused by absorption features that can be described by means of Gaussians [6]. [5] used modified Gaussians to obtain a mathematical solution closer to the physical reality. Each Gaussian is parameterized by a band center, band width and band strength. As described in [6], MGM computations are carried out in energy and natural log reflectance space. Thereby, overlapping absorptions are additive and can be modeled using linear inverse theory. Spectra are modeled in the logarithm of reflectance space as a sum of modified Gaussian distributions superimposed on a baseline continuum. The resulting combinations of Gaussians can then be interpreted in terms of mineralogy.

It has been shown that MGM is able to retrieve modal and/or chemical composition from an unknown spectrum in the case of simple mineralogical assemblages. Successive studies have shown the interest of the MGM approach for planetary surface characterization (e.g., $[7,8,9])$. However, one should note that all the reference studies rely on spectra acquired on laboratory powder samples of controlled composition and granulometry, with grain size between 24 and $250 \mu \mathrm{m}$.

So far, situations addressing more complex mineralogies (i.e. olivine and pyroxene(s) and/or different pyroxene composition) and/or actual rock samples (e.g., [10]) have been little explored by the MGM approach at the exception of a few works (e.g., [10, 11, $12,13,14])$ and significant efforts have still to be made for improving our capability of spectroscopic modeling and interpretation when dealing with real world observations of unknown mafic rock lithologies observed under natural conditions. 
Concerning the influence of plagioclase in MGM deconvolutions, only few studies have been undertaken $[12,14]$.

\section{CRYSTALLINE PLAGIOCLASE MGM MODELING}

Our goal here is to improve the capability of the MGM to realistically model complex mafic mineralogies when considering rock slab surfaces with coarse grained textures, involving plagioclase and mafic crystal field absorptions. Two cases are considered hereafter.

\subsection{Stillwater Complex rock samples}

Extensive tests have been performed on a group of slab spectra (spot size $\sim 1 \mathrm{~cm}^{2}$ ) corresponding to Pl-rich rock samples including two anorthosites and one leuco-gabbro. These spectra present a high albedo, a general blue slope typical of slab spectra and a wide absorption band with a minimum close to $1.25 \mu \mathrm{m}$ indicative of $\mathrm{Fe}^{2+}$ in $\mathrm{Pl}$ and are labelled StC18, StC9, StC13. They have been produced from bidirectional measurements in the visible-near infrared of rocks from the Stillwater layered intrusion [14]. Their mineral abundances have been established from careful point counting under optical microscope (StC18 anorthosite sample has 94.1\% plagioclase $(\mathrm{pl}), 4.1 \%$ clinopyroxene (cpx), 1.8\% zoisite (alteration). StC9 anorthosite sample has $79.0 \% \mathrm{pl}, 5.2 \% \mathrm{cpx}$, $15.7 \%$ zoisite. StC13 leuco-gabbro sample has $81.3 \% \mathrm{pl}, 15.5 \%$ cpx, 3.1\% opx, $0.1 \%$ zoisite).

Examples from [15] are given below (Figs. 1,2,3). For all spectra, the overall blue slope is rather well modelled by the second-order polynomial adjusted on the local maxima along the spectra and used to handle the continuum. The thin hatched line in red corresponds to the initial settings and the solid hatched line shows the MGM modelled continuum after deconvolution. Both lines are quite close and basically overlapping for StC13case. This spectrum also shows much less developed overtone absorption bands, at $1.4,1.9$ and $2.2-2.3 \mu \mathrm{m}$, consistent with the lack or very limited occurrence of secondary minerals (hydrous alteration products).

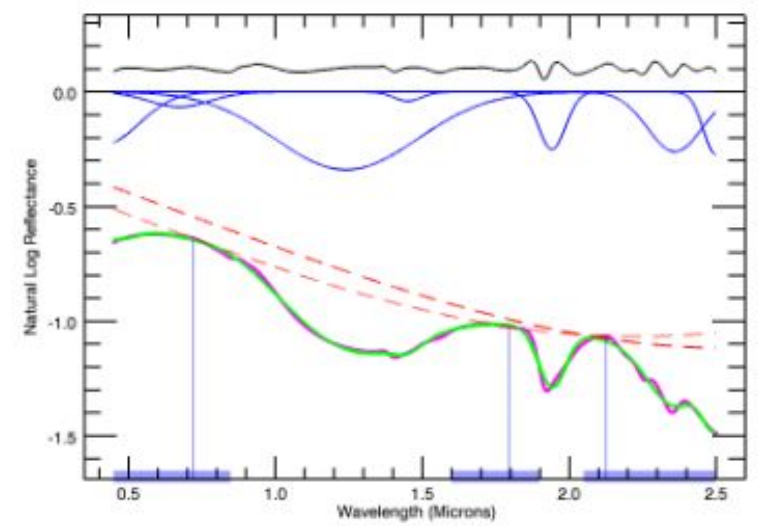

Figure 1. StC18 MGM modelling: ( rms:0.012). 1.25 $\mu \mathrm{m}$ band center at $1242 \mathrm{~nm}$, bandwidth: $568 \mathrm{~nm}$, band depth: -0.34
In all cases, a large absorption band with a minimum around $1.25 \mu \mathrm{m}$ is identified but its band center position may significantly vary. These cases demonstrate that the MGM defined configuration appears to perform well on crystalline pl-rich rock spectra. However, one notes that a weak px contribution associated with pl (up to $15 \%$ for cpx) may be undetected. Further testings are underway on a suite of slab spectra dealing with pl-ol and plpyroxenes assemblages [14, 15].

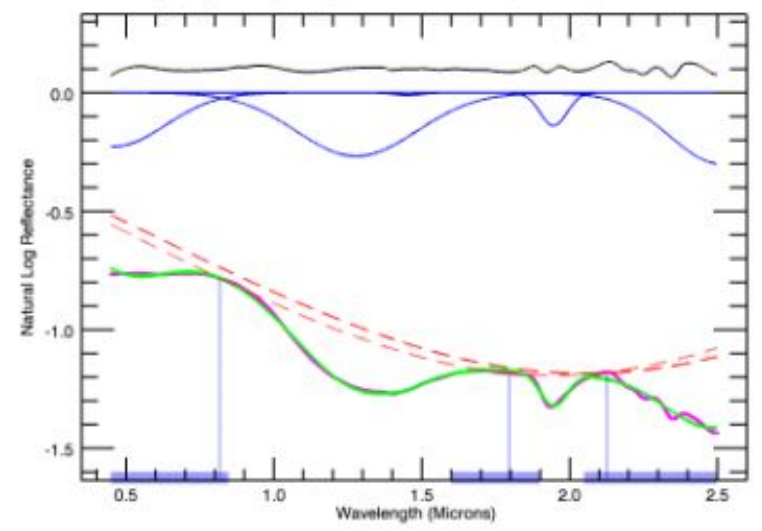

Figure 2. StC9 MGM modelling: (rms:0.010). $1.25 \mu \mathrm{m}$ band center at $1280 \mathrm{~nm}$, bandwidth: $476 \mathrm{~nm}$, band depth: -0.26

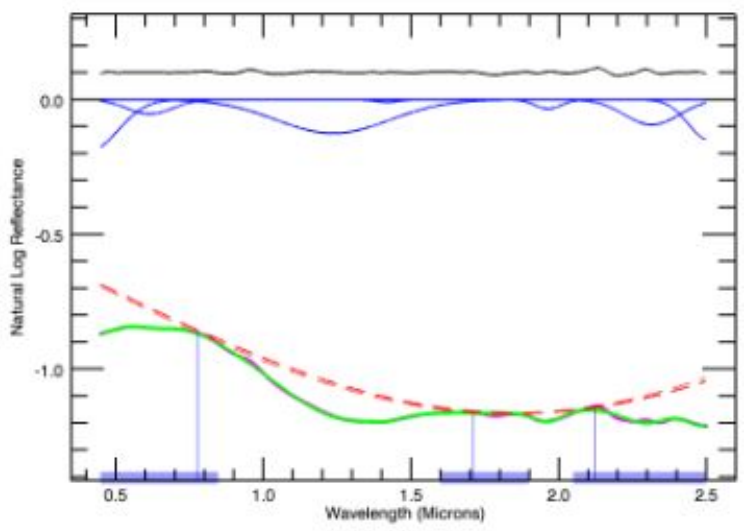

Figure 3. StC13 MGM modelling: (rms:0.008). $1.25 \mu \mathrm{m}$ band center at $1238 \mathrm{~nm}$, bandwidth: $452 \mathrm{~nm}$, band depth: -0.13

\subsection{Oceanic drill core sample}

A second test is made on an hyperspectral cube (measured with HYSPEX instrument) on a $271 \mathrm{~mm}$ long $\mathrm{x} 25 \mathrm{~mm}$ wide core section (see figure below) collected $28 \mathrm{~m}$ below the seafloor at the Hess Deep rift during IODP Expedition 345 (Dec. 2012-Feb. 2013) in recent $(\sim 1 \mathrm{Ma})$ oceanic lower crust off the Galapagos islands [16]). The composition is globally gabbroic, mostly composed of pl feldspar and cpx. Ol and Opx are also present, and their variations define a modal layering, with some ol-rich (troctolitic) layers and other ones devoid of olivine and richer in Opx. Estimated mineral average abundance as a function of depth has been made from optical microscope observation (fig. 4a). Grain size typically ranges from 1 to $5 \mathrm{~mm}$, on the order of the scale of analysis (pixel size on the order of $1 \mathrm{~mm}^{2}$ ) resulting in a collection 
of 8246 pixels on the core (28 (across-track) x 308 (along-track)), giving access to a blend of mafic mineralogical assemblages.

Five examples of mineral detections, ranging from monomineralic to polymineralic cases, including crystalline plagioclase are shown below and compared to the available groundtruth in terms of petrography and mineral composition determined by electron microprobe (Figs. 4 and 5).

\section{C}

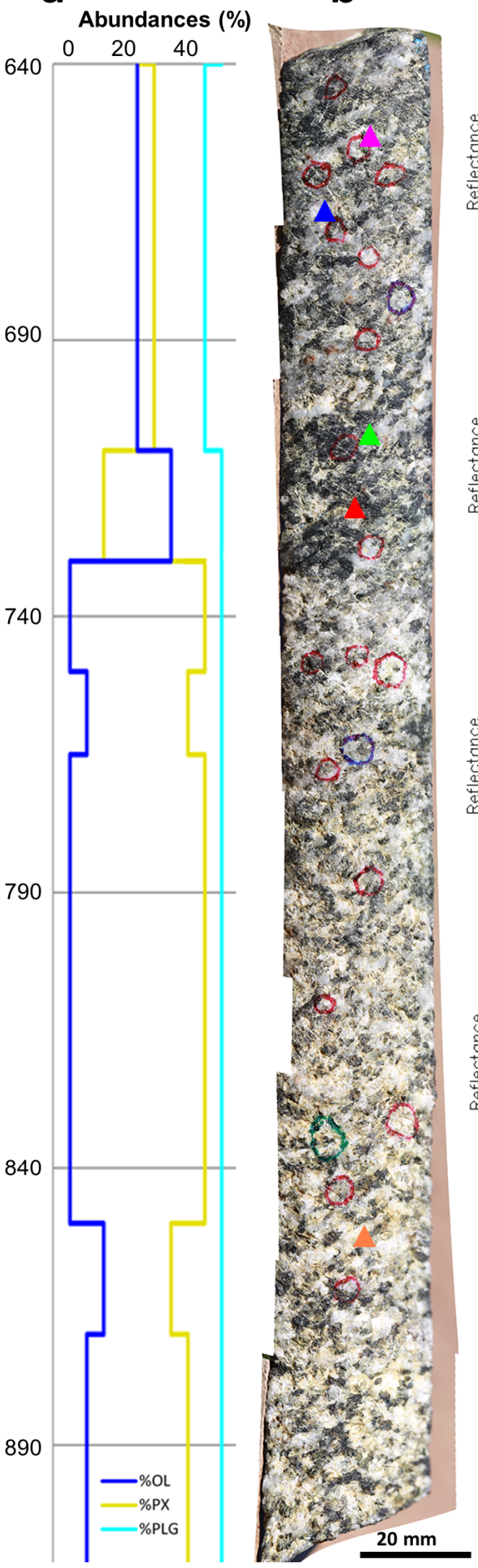

$\Delta$ pixel X029_Y093
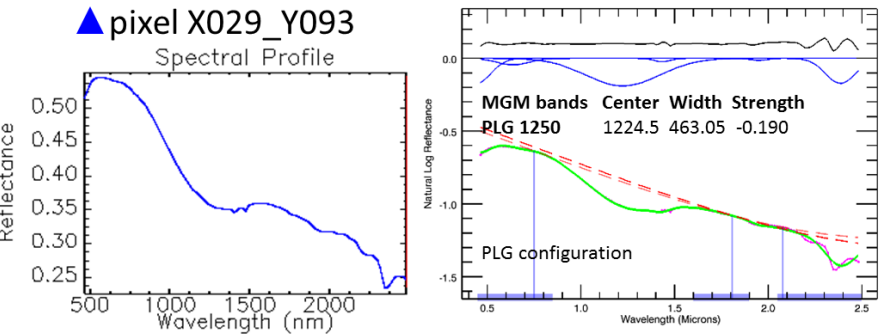

A pixel X040_Y080
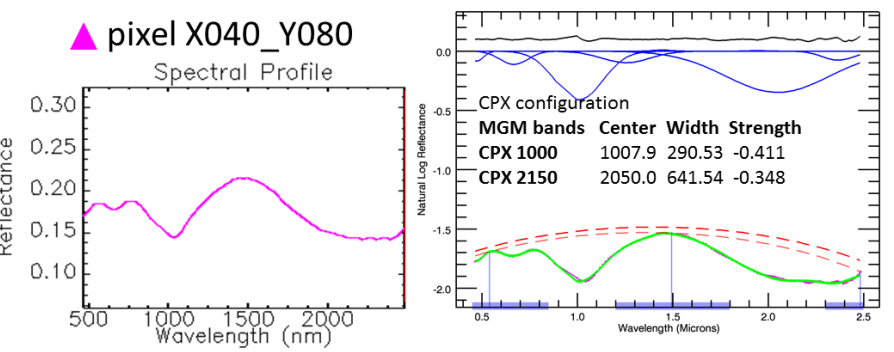

A pixel X037 Y155
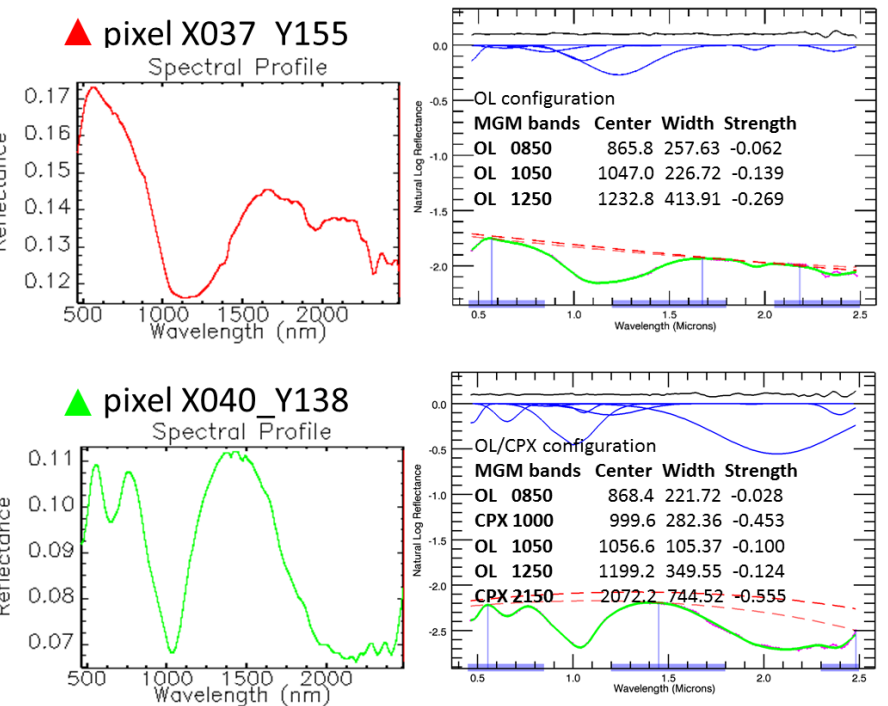

Figure 4. a) Estimated mineral average abundance as a function of depth; b) Image of the core with the location (triangles) of the 5 spectra discussed hereafter and of the macropicture (black rectangle) shown in fig.5; c) and d) Spectrum in blue (Pixel X029_093) is properly modeled as a slightly hydrated plagioclase (rms:0.012), spectrum in purple (Pixel X040_080) is modeled as a Cr-diopside (rms:0.008), spectrum in red (Pixel X037_Y155) is ol-rich (Mg\#80) (rms:0.008), spectrum in green (Pixel X040_Y138) is a Cr-diopside/ol mixture rms:0.011). Spectrum in orange (Pixel X038_Y302) is modeled as a mixture of Pl, cpx and ol (see fig.5).

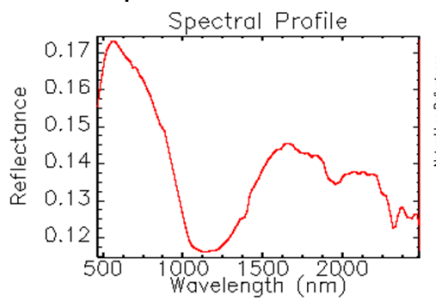



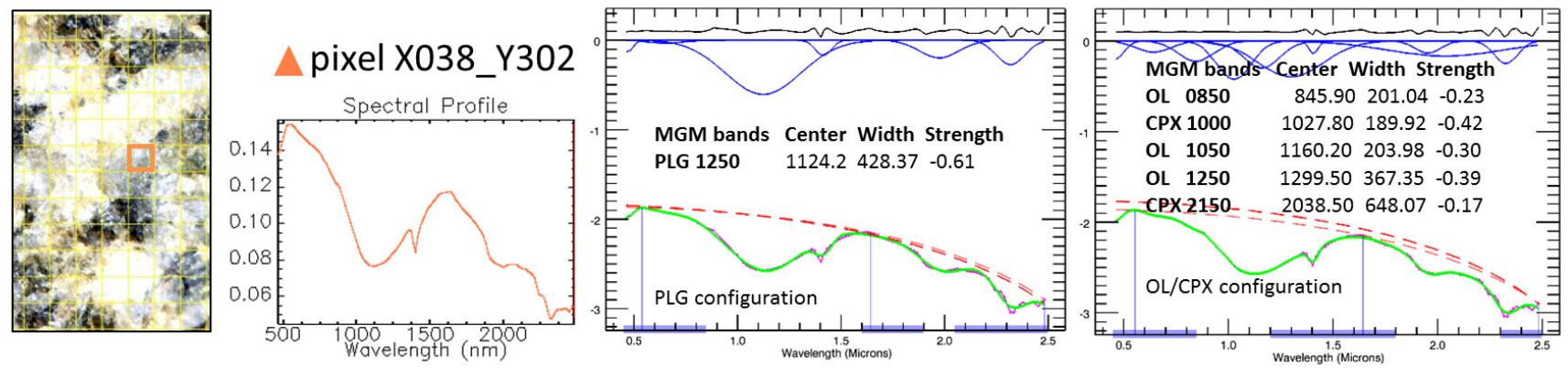

Fig.5. Macropicture revealing mineral textures and assemblages (white color: Pl, dark green-black: Ol, light green-grey: cpx) on a subset of the hyperspectral cube ( $\sim 6 \mathrm{~mm}$ wide x $9 \mathrm{~mm}$ vertical) in the vicinity of the orange square (pixel X038_Y302) (corresponding to the black box on fig.4a) where the MGM deconvolution finds a mixture of $\mathrm{Pl}$ and $\mathrm{Cpx} / \mathrm{Ol}$ in agreement with local point counting estimates. Though not analyzed here, each yellow cell of the grid (scale of analysis on the order of $1 \mathrm{~mm}^{2}$ ) has a spectrum associated with it, corresponding to 8246 individual spectra over the complete core section.

The MGM modeling of the orange spectrum (pixel X038_Y302) (figs. 4 and 5) indicates that this pixel has a heterogeneous mineralogy caused by the presence of (variably altered) plagioclase, clinopyroxene and olivine. Despite higher residuals (respective rms: 0.019 and 0.015) than in simple cases, both PLG and $\mathrm{OL} / \mathrm{CPX}$ configurations appear to provide a quasi correct modeling, the band center positions for $\mathrm{Pl}$ and $\mathrm{Ol}$ absorptions being however disturbed. It is interesting to note that the point counting under the microscope indicates a 40/40/20 mixture for $\mathrm{Pl} / \mathrm{Cpx} / \mathrm{Ol}$ minerals.

\section{CONCLUSIONS AND PERSPECTIVES}

Based on the examples highlighted in this paper, MGM can properly model the typical negative slope of rock slab spectra and discern at microscopic scale the major minerals contribution (ol, cpx, opx), including the detection of crystalline plagioclase, in the spectra across a complex geological sample such as the considered oceanic core.

Plagioclase can be detected by an MGM dedicated configuration only when its abundance is greater than $80 \%$ (see STC9, STC13, STC18 and pixel X29Y93 on the core). Preliminary results also indicate that it is possible to characterize mixtures involving plagioclase in association with mafic minerals. However, weak contribution of pyroxene in association with plagioclase (up to $15 \%$ for clinopyroxene) may be undetected (e.g., STC13).

Though additional work is required and not discussed here [15], it seems that MGM modeled band centers can properly predict olivine compositions in acceptable ranges compared with the microprobe results.

We are currently in the process of generating a systematic mapping at microscopic scale (on the order of $1 \mathrm{~mm}^{2}$ ) of the mineralogical variability found along the core section.

Implications for the future encompass the possibility to make use of microscopic imaging spectroscopy for the characterization of continuous cores from the ocean seafloor acquired with drilling projects. Another direction will be to implement this hyperspectral strategy on $\mathrm{M}^{3}$ spectra with the objective of documenting the petrology of the lunar crust and its layering through characterization of plagioclase and mafic crystal field absorptions.

\section{REFERENCES}

[1] Ohtake, M. et al., Nature, 461, 236-240, 2009 ; Pieters, C.M. et al., Curr. Sci, 96 (4), 500-505, 2009.

[2] Donaldson Hanna et al., JGR-Planets, 119, DOI: 10.1002/2013JE004476, 2014.

[3] Kramer, G.Y. et al, Icarus, 223, 131-148, 2013.

[4] Cheek, L. C. and C.M. Pieters, Am. Mineral., 99, pp. 18711892,2014

[5] Sunshine, J. et al., JGR 95, 6955-696, 1990; Sunshine, J. and Pieters, C., JGR, 98(E5), 9075-9087, 1993.

[6] Clark, R., Roush, T., JGR 89, 6329-6340, 1984.

[7] Mustard, J.F. and Sunshine, J., Science, 267, 1623-1626, 1995.

[8] Mustard, J.F. et al., JGR, 102, 25605-25615, 1997.

[9] Noble, S.K. et al., JGR, 111, E1 1009, 2006 ; Kanner, L.C. et al., Icarus 187, 442-456, 2007.

[10] Pompilio, L. et al., JGR, 112, E01004, 2007 ; Pompilio, L. et al. (2009), Icarus, 201, 781-794, 2009.

[11] Pinet et al., LPSC 37th, Abstract \#1346, 2006 ; Pinet et al., 2007, Mars Conf. 7th, Abstract\#3146, 2007.

[12] Clenet et al., Icarus 213, 404-422, 2011.

[13] Parente, M. et al., Planet. Spa. Sci., 59, (5-6), 423-442, 2011.

[14] Serventi, G. et al., Icarus, 254, pp. 34-55, 2015 ; Carli, C. et al., Am. Mineral., 99, pp. 1834-1848, 2014.

[15] Gou, S. et al., European Lunar Symp. 3rd, abstract book, pp.77-78 and poster, Frascati, Italy, 2015

[16] Gillis, K.M. et al., Nature, 505, pp. 204-207, 2014. 